\title{
O papel consultivo do fonoaudiólogo: algumas reflexões sobre a consultoria colaborativa na escola regular
}

Andréa Carla Machado* Suzelei Faria Bello**

Maria Amelia Almeida***

\section{Resumo}

O sistema de consultoria colaborativa apresenta-se como uma possibilidade de trabalho para colaborar e cooperar com os diversos protagonistas da rede de ensino: escola; professores; família e consultor-especialista, que se propõe a atender a nova demanda do processo inclusivo do século XXI. A consultoria colaborativa é uma proposta na qual os profissionais envolvidos refletem juntos para sanar os problemas da sala de aula. Ao considerar que o fonoaudiólogo está intrinsecamente envolvido com o contexto educacional e trabalha com crianças com dificuldades de comunicação oral, escrita, voz e audição, o presente estudo objetivou verificar os efeitos da cooperação fonoaudiológica numa perspectiva colaborativa no âmbito escolar. Trata-se de uma pesquisa com delineamento questionário - intervenção. O questionário foi aplicado para os professores antes e após a intervenção. Considerou-se que a proposta de Consultoria Colaborativa no âmbito educacional junto com o fonoaudiólogo enriqueceu o processo colaborativo e tornou-se construtivo diante das diferentes demandas educativas. Além disso, forneceu ao professor segurança e apoio no exercício contínuo na sala de aula, propondo reflexões de sua ação, o que maximiza as potencialidades de cada criança e atende às suas diversidades.

Palavras-chave: Colaboração; Fonoaudiologia; Educação Especial.

\section{The speech therapist advisory role: some considerations on} collaborative consulting in regular school

\begin{abstract}
The collaborative consulting system is a work possibility to collaborate and cooperate with the various protagonists in the educational system: school, teachers, family and the specialist consultant, who intends to meet the new demand of the inclusive process of the $21^{\text {th }}$ century. The collaborative consulting is a proposal in which the professionals that are involved reflect together to solve the problems of the classroom. By considering that the speech therapist is intrinsically involved with the educational context and works with children with

\footnotetext{
* Doutoranda em Educação Especial pela Universidade Federal de São Carlos (UFSCar), São Paulo, Brasil.

** Doutoranda em Educação Especial pela Universidade Federal de São Carlos (UFSCar), São Paulo, Brasil.

*** Ph.D em Educação Especial pela Georgia University. Professora do Programa de Pós-Graduação em Educação Especial da Universidade Federal de São Carlos- UFSCar- São Paulo.
} 
difficulties in oral communication, writing, voice and hearing, this study aimed at evaluating the effectiveness of phonoaudiologic cooperation with a collaborative perspective in school context. This is a questionnaire-intervention-questionnaire research for teachers before and after intervention. The proposal of Collaborative Consulting in educational context improved the collaborative process and became constructive with the various educational demands and gave the teacher safety and support in the continuous practice of the classroom, offering reflections which maximize the potential of each child and meet their diversity.

Keywords: Collaboration; Speech Therapy; Special Education.

\section{Introdução}

O trabalho colaborativo apresenta-se como uma direção significativa para solucionar problemas de diversas ordens, relacionados ao ensino-aprendizagem de alunos com necessidades especiais, no contexto escolar inclusivo. Ele pode ser considerado uma estratégia valiosa para a solução de certos problemas no contexto escolar do século XXI.

De acordo com Gargiulo (2003), existem três propostas distintas para o trabalho colaborativo no contexto educacional: ele pode envolver os educadores da escola comum e especialistas (consultoria colaborativa); o educador da escola comum e o educador especial (ensino colaborativo ou co-ensino) ou somente as equipes de serviços da própria escola.

Com o intuito de resolver os problemas no próprio contexto escolar e diminuir os encaminhamentos para especialistas de várias áreas, os profissionais especializados reconhecem a necessidade do apoio ao professor e tornamse, nessa perspectiva, parceiros diante de um trabalho conjunto e colaborador em que tanto o consultor quanto o consultado compartilham saberes com vista ao desenvolvimento de uma solução no contexto escolar.

Portanto, a proposta de consultoria colaborativa consiste em levar o trabalho dos especialistas para dentro da escola. Esse modelo propõe contribuir de forma salutar para que, a partir de alguns problemas vivenciados pelo professor na escola, construam-se possibilidades que potencializem o trabalho do educador e atendam às necessidades do seu alunado. O papel do consultor (especialista) é auxiliar o professor a construir estratégias e rever as potencialidades de seus alunos para que possam, de forma efetiva, desenvolverse academicamente. A colaboração é um modelo para determinar um plano e recomenda-se que seja pensado e apoiado por todos os que estão envolvidos no processo. (MENDES, et al., 2007; KAMPWIRTH, 2003).

Idol et al. (2000, p.1) definem consultoria colaborativa como:

um processo interativo que habilita pessoas com diversas competências para gerar soluções criativas para 
que mutuamente definam os problemas. A maior conseqüência da consultoria é favorecer programas abrangentes e efetivos para os estudantes com necessidades especiais dentro do contexto escolar.

Caplan e Caplan (1993) descrevem algumas características da consultoria colaborativa e acreditam que para que ela ocorra com efetividade é necessário ater-se ao relacionamento entre consultor e consultado, que deve ser coordenado e não hierarquizado. A consultoria pode ser conduzida por uma pequena série de entrevistas em tempos predeterminados e deve ser objetiva e centrada no problema e não nos questionamentos interpessoais do consultado.

Segundo Kampwirth (2003) a consultoria colaborativa dever ser proposta e desenvolvida em etapas, algumas delas podem ser definidas como: 1) encaminhamento: realizado com o professor que necessite de auxílio com seus alunos. O consultor deve explorar um formulário de informação para interar-se do contexto do caso e de todos os dados adicionais que possam auxiliar no processo de discussão durante o trabalho de consultoria; 2) discussão inicial com o professor; 3) observação da classe: para solucionar os problemas de comportamento exige-se um tempo maior de observação e é preciso verificar se a dinâmica do comportamento exige o encaminhamento. É necessário observar se o método que o professor utiliza está sendo adequado e encontrar os principais pontos de interação. Já nos casos de problemas de aprendizagem, a observação pode ser opcional, principalmente se o consultor conhecer como o professor trabalha. Normalmente o método de ensino é o que propõe o currículo. O consultor deve ter bom senso para refletir, observar e coletar os dados importantes; 4) avaliação e encaminhamento dos estudantes; 5) plano de intervenção: neste ponto o consultor deve rever todos os outros encaminhamentos, como a fala com o professor, a observação da criança e da classe, as possibilidades da discussão entre os envolvidos no processo, a avaliação funcional, os problemas e os possíveis passos para as soluções. Com o plano pronto e tendo feito todas as reflexões, recomenda-se que o enfoque colaborativo seja realizado junto com o consultado para poder desenvolver um plano para intervenção; 6 ) monitorar a intervenção: a avaliação deverá ser formativa e acumulativa, ou seja, baseada no processo para determinar as metas da consultoria.

O consultor e o consultado devem concordar com o plano estabelecido e acreditarem no desempenho adequado de cada um e nas metas da avaliação em andamento. Dessa forma, podem fornecer os dados para modificar o programa e determinar sua efetividade.

Sob essa perspectiva e tendo em vista que a Fonoaudiologia é uma ciência que trabalha com os distúrbios da comunicação oral, escrita, voz e audição, seu envolvimento com o contexto escolar torna-se aparente e pode contribuir de forma salutar para, diante do trabalho cooperativo e colaborativo, fornecer novas possibilidades de resolução de problemas dentro do âmbito escolar, principalmente diante de questões relacionadas ao desenvolvimento da linguagem, fala, audição, voz e fluência (MORAIS,2001). 
Segundo Coimbra, Luque e Machado (1991) a Fonoaudiologia Escolar é uma área com importante participação ativa na educação. Outros autores clarificados adiante fazem seus contrapontos. Berberian (2000) contrapõe-se à ideia de que a Fonoaudiologia surgiu na década de 1960, com a criação dos primeiros cursos universitários. Este estudo nos leva a conhecer a história, anterior a este marco oficial, do processo social em que ocorreu a constituição das práticas fonoaudiológicas, que eram estreitamente ligadas ao processo educacional entre os anos 1920 e 1940. A autora mostra que este encontro histórico entre a Educação e a Fonoaudiologia deu-se numa época de controle sistemático da língua pátria, nos bancos escolares, para neutralizar a influência advinda dos imigrantes. A institucionalização dos distúrbios de linguagem e sua conceituação, fortemente ligadas a esse controle da língua, são apontadas na pesquisa que aborda o contexto sociocultural da época.

Kyrillos, Martins e Ferreira (1997) afirmam que a experiência da atuação do fonoaudiólogo associada à do professor exige uma integração de conhecimentos, cooperação, entendimento e discussão de exercícios de trabalho escolar, o que só tende a contribuir para o desenvolvimento dos alunos. Então, o fonoaudiólogo pode identificar a natureza dos "distúrbios" sinalizados pelos profissionais da escola e promover uma reflexão, no sentido de evitar os rótulos e todas as consequências implicadas. Para tanto, o profissional precisa estabelecer parceria com os profissionais da escola, discutir e avaliar as suas reais necessidades. Quanto à atuação em equipe, é necessário ter uma perspectiva coletiva, traçar metas conjuntas para melhor atender ao grupo de alunos, participar da elaboração do planejamento escolar, das reuniões de pais e professores, entre outros. Deve também orientar os professores como forma de garantir um processo de formação consciente e reflexiva.

Numa perspectiva de assessoria, para o trabalho fonoaudiológico no contexto escolar torna-se imperativo compartilhar seus conhecimentos sobre prevenção, aquisição e desenvolvimento de linguagem com os professores, o que trará benefícios ilimitados ao ambiente escolar (MORAIS, 2001). A parceria entre o professor e o fonoaudiólogo torna-se fundamental, uma vez que o professor está em contato mais próximo e constante com a criança (SACALOSKI, et al. 2001).

Observa-se, segundo Zorzi (2001), que a área de Fonoaudiologia Escolar encontra-se diante de um crescimento significativo e, portanto, se faz necessário caracterizar a atuação do fonoaudiólogo em escolas que propõem ações pedagógicas de cooperação e complementação e não de tratamento.

Segundo este mesmo autor, a ação fonoaudiológica na esfera educacional tem uma nova concepção frente aos conhecimentos que esse profissional dispõe nas áreas de comunicação oral e escrita. Ele deveria promover e otimizar sua atuação no sentido de prevenir problemas no contexto educacional. No entanto, para Morais (2001) a Fonoaudiologia precisa refletir sobre suas ações visando o (re)conhecimento de sua competência nas escolas. 
O estudo realizado por Calheta e Silva (2005) teve a intenção de verificar as ações do fonoaudiólogo na escola para averiguar a proposta de assessoria vinculada à ideia de promoção de saúde ou prevenção. Concluiu-se, neste estudo, que é essencial a busca por uma atuação fonoaudiológica nas escolas, com a intenção de potencializar a construção do conhecimento para todos os sujeitos inseridos na relação entre Fonoaudiologia e Educação.

De acordo com Luzardo e Nemr (2006) a Fonoaudiologia Escolar visa à criação de condições favoráveis e eficazes para que as habilidades e capacidades de cada criança possam ser demonstradas. Ao considerar a escola 0 lócus privilegiado para a aquisição da linguagem oral e escrita, este espaço torna-se crucial na atuação do fonoaudiólogo.

O professor, agente potencializador do processo ensino-aprendizagem, acompanhado pela assessoria fonoaudiológica que esteja compondo um trabalho de colaboração, podem ser fortes aliados para a elaboração de estratégias de incentivo das habilidades comunicativas dos alunos e também na identificação, o quanto antes, dos desvios apresentados por eles. (MARANHÃO, et al., 2009)

A Fonoaudiologia apresenta um posicionamento majoritário em sua parceria fonoaudiologia/educação, visto que há tendências de pesquisas que primam por esta relação, tais como aquelas apresentadas por Collaço (1991), que relata sua participação no trabalho em equipe numa escola de São Paulo durante dez anos - entre 1968 e 1978 - com o objetivo de orientar professores quanto aos aspectos referentes à alfabetização, bem como prevenir as alterações de fala e escrita.

Bittar (1991) expõe em sua pesquisa três experiências realizadas em escolas particulares no período de 1974 a 1979, tendo como objetivos: orientar professores quanto ao conteúdo a ser trabalhado em comunicação e expressão; detectar, através de triagens, as dificuldades de linguagem oral/escrita; orientar e realizar o encaminhamento para o tratamento do aluno e orientação aos pais, por meio de palestras, sobre o desenvolvimento adequado da linguagem.

Pereira, Santos e Osborn (1995) destacam em suas pesquisas de um Programa de Saúde Escolar, que a atuação do fonoaudiólogo na escola engloba algumas vertentes, tais como: a) orientação a pais e professores sobre o processo de desenvolvimento normal e sensibilização para estimular processamento auditivo, linguagem e produção fonoarticulatórios; b) exames fonoaudiológicos que avaliam emissão e recepção oral, voz, respiração, órgãos fonoarticulatórios e processamento auditivo; c) realização de testes para leitura e escrita; d) encaminhamento dos alunos com alterações para reavaliação e tratamento; e) orientação a pais e professores após as avaliações. 
Canepa (1999) apresentou em sua pesquisa um histórico sobre a atuação fonoaudiológica pioneira em uma escola de São Paulo, que apresentava uma visão humanista do indivíduo. Descreveu o setor fonoaudiológico constituído neste espaço e apresentou os objetivos de profilaxia e encaminhamentos, quando necessários, acerca das dificuldades que não eram passíveis de trabaIho no âmbito escolar.

Trabalhos mais recentes como o de Oliveira et al. (2002) descreveram a prática fonoaudiológica escolar realizada nos anos de 2001 e 2002. Somente no ano de 2002 a atuação volta-se às Escolas Municipais de Educação Infantil (EMEIs), retratando o caráter preventivo e a relação de cooperação com professores e pais, envolvendo os distúrbios de fala e linguagem, as alterações do sistema sensório-motor-oral e os hábitos orais inadequados. Para o desenvolvimento da prática fonoaudiológica, nesta proposta, foram realizados encontros com todos os professores, com o intuito de informar sobre desenvolvimento da linguagem e aspectos relacionados. Os pais também recebiam atenção por parte do fonoaudiólogo quando havia a necessidade de encaminhamento, sendo direcionados para a Unidade de Saúde do Município.

Portanto, a Fonoaudiologia e a Educação permitem desvelar um espaço de atuações articuladas e com parcerias que agregam valores no sentido de possibilitar às diferentes populações, absorver as especificidades de ambas as áreas e enriquecer as atuações e minimizar as dificuldades encontradas. Desvenda-se a necessidade de colaboração e cooperação entre todos participantes do processo educacional - fonoaudiólogos, pais, professores, alunos, coordenadores pedagógicos, diretores, comunidade e outros - na tentativa de tornar o ambiente educacional flexível e potencializar as habilidades de cada aluno para um amplo aprendizado.

Para tanto, o presente trabalho tem o intuito de responder a seguinte questão de pesquisa: qual a relação do trabalho fonoaudiológico na perspectiva da consultoria colaborativa junto ao professor da escola regular?

Diante desta indagação, o principal objetivo foi verificar a eficácia da intervenção fonoaudiológica numa perspectiva colaborativa no âmbito escolar e contribuir para um processo salutar na reflexão da atuação fonoaudiológica voltada para o processo inclusivo.

Justifica-se a atuação do fonoaudiólogo como profissional capaz de cooperar para propiciar uma escola inclusiva que reconheça as múltiplas dimensões do sujeito, suas diversidades e habilidades. Reconhece-se que a modificação da percepção do professor quanto ao trabalho fonoaudiológico decorre da necessidade de torná-lo participativo da ação fonoaudiológica no contexto escolar.

Além de averiguar o conhecimento dos professores sobre o trabalho da consultoria colaborativa este trabalho propõe o modelo de consultoria 
colaborativa numa escola privada e verifica os efeitos da consultoria colaborativa na perspectiva fonoaudiológica junto aos professores.

\section{Método}

Participaram desse estudo duas professoras do Ensino Fundamental de uma escola privada do interior do Estado de São Paulo, cada uma com um aluno que apresentava dificuldades de comunicação oral. Também participou um consultor - fonoaudiólogo, isto é, o próprio pesquisador.

A participação dos(as) professores(as) foi voluntária. A inclusão dos alunos na pesquisa foi realizada mediante assinatura da autorização dos pais, encaminhamento da professora por motivo de dificuldades comunicativas no contexto escolar, condição essencial para a inclusão e seleção da criança na pesquisa, verificada pelo desempenho no Teste de Linguagem Infantil (ABFW).

Os encontros da consultoria colaborativa, ou seja, os diálogos entre pesquisador(a)/especialista e professores, ocorreram na própria escola em período combinado, que não prejudicou o andamento das aulas, com duração de 30 a 40 minutos durante três meses, perfazendo um total de dez encontros.

Para coleta de dados foram utilizados os seguintes instrumentos, os quais estão descritos a seguir:

1-Professores: a) questionário sobre o conhecimento do conceito de consultoria que foi aplicado antes e após o programa de consultoria; b) ficha de encaminhamento do aluno para Consultoria Colaborativa, também aplicado no início e no fim do processo; c) diário de atividades para investigação pós-intervenção da percepção dos(as) professores(as) participantes sobre a consultoria prestada .

2-Alunos: a) Teste ABFW - teste de linguagem infantil. O teste de linguagem infantil, ABFW, aborda as áreas de Fluência, Vocabulário, Pragmática e Fonologia e foi elaborado por Claudia Regina Furquim de Andrade, Débora Maria Befi-Lopes, Fernanda Dreux Miranda Fernandes e Haydée Fiszbein Wertzner, Docentes do Curso de Fonoaudiologia da Faculdade de Medicina da Universidade de São Paulo (FMUSP). Ele possibilita avaliar os aspectos importantes da linguagem infantil.

Os dados foram analisados conforme sua especificidade. Os resultados dos instrumentos aplicados em situação de pré e pós-teste foram comparados e descritos por meio de tabelas.

De acordo com Brantlinger et al. (2005) a investigação colaborativa tem um caráter qualitativo e progride através da prática conjunta com os atores da população pesquisada e do pesquisador. 
Andréa Carla Machado - Suzelei Faria Bello Maria Amelia Almeida

Esta pesquisa foi aprovada pelo Comitê de Ética da Universidade Federal de São Carlos - Comissão Nacional de Ética em Pesquisa - CONEP, recebendo aprovação por meio do seguinte protocolo: CAAE 2003.0.000.135-09.

\section{Resultado e discussão}

Na Tabela 1 pode-se visualizar o perfil das professoras que participaram desta pesquisa, reafirmando que a participação e inserção na proposta foi voluntária.

Tabela 1: perfil dos participantes

\begin{tabular}{|c|c|c|}
\hline Dados Gerais & Professora I & Professora II \\
\hline Sexo & Feminino & Feminino \\
\hline Idade & 31 & 25 \\
\hline Formação & Pedagogia & Pedagogia \\
\hline Especialização & - & Psicopedagogia \\
\hline Sala & $\begin{array}{l}2^{\circ} \text { ano do ensino } \\
\text { fundamental }\end{array}$ & $\begin{array}{l}2^{\circ} \text { ano do ensino } \\
\text { fundamental }\end{array}$ \\
\hline Escola & Privada & Privada \\
\hline
\end{tabular}

No primeiro momento da consultoria foi proposta às professoras uma visão de todo o trabalho a ser efetuado e como se caracteriza o programa de consultoria, delineando seu conceito e proposta.

No início do processo de consultoria foi fornecido às professoras um questionário com sete questões, duas fechadas e cinco abertas, que envolviam o conhecimento sobre a proposta, bem como se o fonoaudiólogo pode contribuir nesse formato de trabalho.

Após dez encontros, dos quais dois foram semanais e os demais quinzenais, foi aplicado novamente o mesmo questionário acrescido de duas questões abertas. Na tabela 2, podem-se verificar as respostas das professoras diante do trabalho realizado. 
Tabela 2. Pré e Pós-teste

\begin{tabular}{|c|c|c|c|c|}
\hline \multirow{2}{*}{$\begin{array}{c}\text { Temas } \\
\text { abordados }\end{array}$} & \multicolumn{2}{|c|}{ Pré-teste } & \multicolumn{2}{|c|}{ Pós-teste } \\
\hline & Professora I & Professora II & Professora I & Professora II \\
\hline $\begin{array}{c}\text { Conhece o } \\
\text { conceito de } \\
\text { C.C? }\end{array}$ & Não & Não & Sim & Sim \\
\hline $\begin{array}{l}\text { O que entende } \\
\text { por consultoria } \\
\text { colaborativa? }\end{array}$ & - & - & $\begin{array}{l}\text { Equipe de } \\
\text { profissionais } \\
\text { dispostos a } \\
\text { trabalhar na } \\
\text { escola, junto com } \\
\text { o professor. }\end{array}$ & $\begin{array}{l}\text { União de } \\
\text { professores e } \\
\text { outros } \\
\text { profissionais, } \\
\text { que juntos } \\
\text { trabalham com } \\
\text { os mesmos } \\
\text { objetivos. }\end{array}$ \\
\hline $\begin{array}{c}\text { Quando } \\
\text { solicitar a CC? }\end{array}$ & $\begin{array}{c}\text { Quando tiver } \\
\text { auno com } \\
\text { dificuldade no } \\
\text { desenvolvimento } \\
\text { global. }\end{array}$ & $\begin{array}{c}\text { Dificuldade de } \\
\text { comportamen-t- } \\
\text { o e } \\
\text { aprendizagem. }\end{array}$ & $\begin{array}{l}\text { Dificuldade de } \\
\text { aprendizagem, } \\
\text { comunicação e } \\
\text { comportamento. }\end{array}$ & $\begin{array}{l}\text { Dificuldade de } \\
\text { comportamento, } \\
\text { aprendizagem e } \\
\text { comunicação. }\end{array}$ \\
\hline $\begin{array}{l}\text { A CC pode ser } \\
\text { uma estratégia } \\
\text { colaboradora? }\end{array}$ & $\begin{array}{l}\text { Sim, deve partir } \\
\text { da realidade } \\
\text { escolar. }\end{array}$ & $\begin{array}{c}\text { Sim, deve ser } \\
\text { um trabalho } \\
\text { conjunto. }\end{array}$ & $\begin{array}{c}\text { Trabalho é } \\
\text { desenvolvido em } \\
\text { parceria, focando } \\
\text { nas dificuldades } \\
\text { do aluno. }\end{array}$ & $\begin{array}{c}\text { O trabalho é } \\
\text { conjunto, pois } \\
\text { sozinho o } \\
\text { professor tem } \\
\text { mais } \\
\text { dificuldades de } \\
\text { lidar com as } \\
\text { dificuldades. }\end{array}$ \\
\hline $\begin{array}{c}\text { O que o } \\
\text { consultor pode } \\
\text { oferecer? }\end{array}$ & $\begin{array}{c}\text { Caminhos e } \\
\text { auxilios no } \\
\text { trabalho durante } \\
\text { a alfabetização. }\end{array}$ & $\begin{array}{c}\text { Estratégias } \\
\text { adequadas } \\
\text { frente à } \\
\text { dificuldade de } \\
\text { fala. }\end{array}$ & $\begin{array}{l}\text { Estratégias, } \\
\text { auxilio, clareza e } \\
\text { reflexão do } \\
\text { trabalho. }\end{array}$ & $\begin{array}{l}\text { Estratégias, } \\
\text { apoio e } \\
\text { caminhos } \\
\text { diferentes. }\end{array}$ \\
\hline $\begin{array}{c}\text { O consultor } \\
\text { fonoaudiólogo } \\
\text { pode } \\
\text { contribuir? }\end{array}$ & Sim & Sim & Sim & Sim \\
\hline $\begin{array}{c}\text { Como o } \\
\text { fonoaudiólogo } \\
\text { pode } \\
\text { colaborar? }\end{array}$ & $\begin{array}{c}\text { Estratégias } \\
\text { diferentes } \\
\text { focadas na falta } \\
\text { para facilitar o } \\
\text { aprendizado. }\end{array}$ & $\begin{array}{l}\text { Colaboração e } \\
\text { suporte nas } \\
\text { dificuldades } \\
\text { encontradas. }\end{array}$ & $\begin{array}{l}\text { Desenvolvendo } \\
\text { trabalho junto com } \\
\text { o professsor, } \\
\text { propondo } \\
\text { atividades } \\
\text { facilitadoras. }\end{array}$ & $\begin{array}{c}\text { Trocando } \\
\text { informações, } \\
\text { tanto das } \\
\text { estratégias } \\
\text { focadas no } \\
\text { aluno, como } \\
\text { também dicas } \\
\text { para lidar com } \\
\text { as dificuldades } \\
\text { de fala da } \\
\text { criança }\end{array}$ \\
\hline
\end{tabular}


...continuação tabela 2

\begin{tabular}{|c|c|c|c|c|}
\hline $\begin{array}{c}\text { O trabalho } \\
\text { contribuiu com } \\
\text { os demais } \\
\text { alunos? }\end{array}$ & - & - & $\begin{array}{c}\text { Sim, pois havia } \\
\text { outros pasos de } \\
\text { dificuldades que, } \\
\text { com as } \\
\text { estratégias, foram } \\
\text { sanados e/ou } \\
\text { identificados. }\end{array}$ & $\begin{array}{c}\text { Sim. Acabamos } \\
\text { trabalhando com } \\
\text { a sala e as } \\
\text { informações são } \\
\text { valiosas. }\end{array}$ \\
\hline $\begin{array}{c}\text { Sugestões } \\
\text { para o trabalho. }\end{array}$ & - & - & $\begin{array}{c}\text { Toda a escola } \\
\text { deveria ter esse } \\
\text { profissional. }\end{array}$ & $\begin{array}{c}\text { Ter outros } \\
\text { profissionais } \\
\text { além da } \\
\text { fonoaudióloga na } \\
\text { escola. }\end{array}$ \\
\hline
\end{tabular}

A priori nenhuma professora conhecia a proposta de consultoria colaborativa a ser realizada, porém ao final de dez encontros elas passaram a conhecer e elencaram possibilidades que podem ser dinamizadas com a proposta da consultoria fonoaudiológica.

De acordo com Kampwirth (2003), no modelo colaborativo deve-se evitar a relação de dependência entre o consultado e o consultor, que pode facilmente ser desenvolvida. Existem algumas características para o modelo colaborativo se efetivar e que compreende desde a coordenação das condições até o envolvimento do consultado durante todo o processo.

A colaboração e a cooperação são fundamentais para a implementação e o monitoramento do processo. O aluno é a chave do plano e determina suas modificações futuras. Na implementação, todos (estudante, a classe, o professor, o consultor) e demais envolvidos devem ter a compreensão do seu papel.

Essa relação de cooperação ficou clarificada na medida em que os professores compreenderam, no pós-teste, que a consultoria traz em si o modelo de cooperativismo ao relatarem que é a "união de professores e outros profissionais, que juntos trabalham com os mesmos objetivos". Tal visão perpassa pelos achados de Friend e Cook (1999), quando delineia as condições necessárias para que ocorra a colaboração. Para esses autores, deve ocorrer a interação de no mínimo dois parceiros, engajados num processo de tomada de decisão com objetivos comuns e deve pautar-se em: a) existência de um objetivo comum; b) equivalência entre participantes; c) compartilhamento de responsabilidades e d) voluntarismo.

Destarte a Fonoaudiologia emerge como uma proposta que pode auxiliar no processo educacional de crianças com dificuldades de comunicação oral e, para tanto, vale destacar que o fonoaudiólogo inserido no contexto educacional tem conquistado este espaço, assumindo este ambiente como um vasto 
campo de inter-relações. De acordo com Maranhão et al. (2009) a fonoaudiologia escolar propõe criar condições favoráveis e eficazes para que a capacidade de cada um possa ser desenvolvida.

Nesse contexto escolar, o fonoaudiólogo pode trazer benefícios ilimitados com seus conhecimentos sobre aquisição e desenvolvimento de linguagem oral, como aponta pesquisa realizada por Maranhão et al. (2009) ao verificar que existe a necessidade do fonoaudiólogo assumir seu papel nas escolas, estabelecendo parcerias com os professores. Este fato pode ser demarcado nesta pesquisa ao observar que as duas professoras consideraram que 0 fonoaudiólogo pode contribuir com estratégias diferentes que envolvam fala e linguagem.

Outros estudos têm encontrado resultados positivos sobre a colaboração, que podem beneficiar todos os estudantes e também os professores que se sentem renovados e entusiasmados (RIPLEY, 1997; SALEND; DUHANEY, 1999). Além disso, estes estudos relatam melhorias dos alunos com alguma necessidade educacional especial quanto a seu desempenho acadêmico, autoestima e relacionamento com os pares.

Estes achados corroboram com os dados encontrados nesta pesqui$\mathrm{sa}$, pois as professoras relataram que as estratégias colaboraram com toda a sala e não somente com os alunos em foco, além de verificar a mudança de atitude dos alunos com seus pares, perante as suas alterações de comunicação.

Uma observação relevante perpassa pela ação e reflexão da atuação profissional do professor, diante da proposta de consultoria colaborativa, que possibilita operacionalizar uma ação visando à prática educativa transformadora, como pontua Jesus (2008), que demarca a "necessidade de se criar condições de reflexão crítica individuais e coletivas" (JESUS, 2008, p. 80).

O encaminhamento das crianças-alvo foi realizado antes e depois do processo de consultoria pelas professoras, como demonstra a tabela 3. 
Andréa Carla Machado - Suzelei Faria Bello Maria Amelia Almeida

Tabela 3. Encaminhamento das professoras.

\begin{tabular}{|c|c|c|c|c|}
\hline Encaminhamento & \multicolumn{2}{|c|}{ Aluno I } & \multicolumn{2}{|c|}{ Aluno II } \\
\hline Sexo & \multicolumn{2}{|c|}{ Masculino } & \multicolumn{2}{|c|}{ Masculino } \\
\hline Idade & \multicolumn{2}{|c|}{7 anos e 6 meses } & \multicolumn{2}{|c|}{7 anos e 2 meses } \\
\hline $\begin{array}{c}\text { Nível de } \\
\text { escolaridade }\end{array}$ & \multicolumn{2}{|c|}{$1^{\circ}$ ano do ensino fundamental } & \multicolumn{2}{|c|}{$1^{\circ}$ ano do ensino fundamental } \\
\hline \multirow{2}{*}{$\begin{array}{l}\text { A criança recebe } \\
\text { algum tipo de } \\
\text { apoio } \\
\text { especializado? }\end{array}$} & Antes & Depois & Antes & Depois \\
\hline & Não & Sim & Não & Sim \\
\hline Comunicação & $\begin{array}{l}\text { O aluno fica } \\
\text { constrangido } \\
\text { em se } \\
\text { comunicar em } \\
\text { grupo. }\end{array}$ & $\begin{array}{l}\text { O aluno se } \\
\text { comunica } \\
\text { mesmo com } \\
\text { dificuldade. }\end{array}$ & $\begin{array}{l}\text { Mesmo com as } \\
\text { dificuldades } \\
\text { tenta se fazer } \\
\text { entender. }\end{array}$ & $\begin{array}{c}\text { Procura utilizar } \\
\text { as estratégias } \\
\text { de fala. }\end{array}$ \\
\hline $\begin{array}{c}\text { Interação } \\
\text { comunicativa com } \\
\text { seus pares }\end{array}$ & $\begin{array}{l}\text { Fica muito } \\
\text { nervoso } \\
\text { quando não é } \\
\text { entendido. }\end{array}$ & $\begin{array}{l}\text { Quando não é } \\
\text { entendido, } \\
\text { procura } \\
\text { estratégias } \\
\text { para relatar o } \\
\text { que deseja. }\end{array}$ & $\begin{array}{l}\text { Interage, mas } \\
\text { diante da } \\
\text { dificuldade se } \\
\text { cala. }\end{array}$ & $\begin{array}{l}\text { Utiliza-se de } \\
\text { novos recursos } \\
\text { para se fazer } \\
\text { entender. }\end{array}$ \\
\hline
\end{tabular}

Como complemento do trabalho, realizou-se a avaliação ABFW apenas em dois aspectos, vocabulário e fonologia, a fim de direcionar a proposta de consultoria.

Vale destacar que a comunicação verbal pode ser entendida como aquela associada à palavra expressa e que a fala com dificuldades é aquela que acarreta uma comunicação não efetiva, podendo a forma de falar atrapalhar a compreensão do conteúdo comunicativo. (SILVA, 2006).

Por meio desses achados, foram elaboradas diferentes estratégias junto às professoras, para auxiliá-las na relação de fala desses alunos com o 
grupo e com a própria professora, bem como aplicativos que, dentro do cronograma de aula, trabalhassem as dificuldades de fala apresentada pelos alunos.

Contudo, pode-se observar que a dificuldade de fala dos alunos encontra-se como limitadora da interação com os pares, um ponto discutido durante a consultoria para que o professor tenha atributos para intermediar as rotinas diárias de sala de aula.

Vale destacar que os aspectos comunicativos apresentados pelos alunos podem ser entendidos como um demonstrativo, pois algumas dificuldades nem sempre podem ser sanadas sem a intervenção terapêutica do fonoaudiólogo em contexto extra-escolar, porém o destaque é para a interação professor-fonoaudiólogo no contexto educacional, trabalhando para juntos lidarem com as dificuldades de alunos e facilitar o caminho da interação alunoprofessor-pares, visando um processo de ensino-aprendizagem salutar.

\section{Conclusão}

Considerou-se que a proposta de Consultoria Colaborativa no âmbito educacional junto com o fonoaudiólogo enriqueceu o processo colaborativo e tornou-se construtivo diante das diferentes demandas de atendimentos, no contexto educacional. Além disso, a proposta pode proporcionar ao professor maior segurança e apoio no exercício contínuo de sala de aula, propondo reflexões sobre suas práticas, o que maximiza as potencialidades de cada criança e atende as suas diversidades.

Outro ponto observado nessa proposta foi a possibilidade da colaboração auxiliar, não só para os alunos alvos, mas para cooperar com todo o coletivo, além de fornecer novos subsídios frente aos contextos de linguagem, comunicação e fala das professoras.

Portanto, na perspectiva da consultoria colaborativa, especificamente a interação entre Fonoaudiólogo e Professor pode contribuir para uma escola que atenda a diversidade e traga no trabalho conjunto a possibilidade que permeia a nova concepção inclusiva, visando o ensino e a aprendizagem diante das diversas potencialidades dos alunos.

Contudo, vale ressaltar que nessa proposta cabem ainda mais estudos para delinear com clareza o campo de atuação conjunta desses profissionais.

\section{Referências}

BERBERIAN, A. P. Fonoaudiologia e Educação: um encontro histórico. São Paulo: Summus, 2000. 
BITTAR, M. L. Fonoaudiologia escolar: relato de uma experiência. In: FERREIRA, L. P. (Org.) O fonoaudiólogo e a escola. São Paulo: Summus, 1991.

BRANTLINGER, E.; JIMENEZ, R. KLINGNER, J.; PUGACH, M; RICHARDSON, V. Qualitative Studies in Special Education. exceptional children, v.71; n. 2; p. 196-207, 2005.

CALHETA, P. P.; SILVA, T. O. F. da. Reflexões sobre assessoria fonoaudiológica na escola. Distúrbios da Comunicação, São Paulo, 17(2): 225-232,2005.

CANEPA, R. O contato dos fonoaudiólogos com a escola: o encontro clinico pedagógico. In: CONGRESSO INTERNACIONAL DE FONOAUDIOLOGIA, 4., 1999, São Paulo. Anais. São Paulo, 1999. p. 465.

CAPLAN, G.; CAPLAN, R. B. Mental health consultation and collaboration. San Francisco: Jossey-Bass, 1993.

COIMBRA, L. M. V.; LUQUE, M. C. F.; MACHADOS. A. F. Fonoaudiologia escolar: um campo de trabalho em movimento. In: FERREIRA, L. P. O fonoaudiólogo e a escola. São Paulo: Summus, 1991. p.61-65.

COLLAÇO, N. L. Fonoaudiologia escolar: as origens de uma proposta. In: FERREIRA, L. P. O fonoaudiólogo e a escola. São Paulo: Summus, 1991.

FRIEND, M.; COOK, L. Collaboration as a predictor for success in reform. Journal of education and psychological consultation, n.1, p. 69-86, 1990

GARGIULO, R. M. Education on contemporary society: an introduction to exceptionality . Thomson Learning: United Station, 2003.

JESUS, D. M. Formação de professores para a inclusão escolar: instituindo um lugar de conhecimento. In: E.G. Mendes; M.A. Almeida; M.C.P.I. Hayashi, (Orgs.). Temas em Educação Especial: conhecimentos para fundamentar a prática. Araraquara: Junqueira \& Marin; Brasília, DF: CAPES-PROESP. 2008, p.75-82.

IDOL, L.; NEVIN, A.; WHITCOMB, P. P. Collaborative Consultation. Austin: Pro-ed,2000.

KAWPWIRTH, T. J. Collaborative consultation in the schools: effective practices for students with learning and behavior problems. New Jersey: Merril Prentice Hall, 2003.

KYRILLOS, L. C. M.; MARTINS, K. L.; FERREIRA, P. E. A. Fonoaudiologia e escola: a aprendizagem de uma visão preventiva. In: LAGROTTA, M. G. M.; CÉSAR, C. P. H. A. R. Fonoaudiologia nas instituições. São Paulo: Lovise, 1997. p.93-97.

LUZARDO, R.; NEMR, K. Instrumentalização fonoaudiológica para professores da educação infantil. Rev CEFAC. 2006; 8(3):289-300. 
MARANHÃO, P. C. S.; PINTO, S. M. P. da C.; PEDRUZZI. C. M. Fonoaudiologia e Educação Infantil: uma parceria Rev. CEFAC. 2009 JanMar; 11(1):59-6.

MENDES, E. G.; TOYODA, C, Y.; BISACCIONE, P. S.O.S. Inclusão escolar: Avaliação de um programa de consultoria colaborativa com base em diários de campo. In: JESUS, D. M. et al. Inclusão praticas pedagógicas e trajetórias de pesquisa. Porto Alegre: Editora Mediação, 2007.

MORAIS, K. W. Repensar sobre o papel do fonoaudiólogo no âmbito escolar [periódico online]. 2001. Disponível em: http://www.fonoaudiologia.com/ trabalhos/artigos/ artigo-035/index.htm.

OLIVEIRA, L. N, GOSSLER, M. A. S, PRESTO, N. O. Fonoaudiologia em educação: enfoque interdisicplinar. Rev Fonoaudiol 2002.

PACHECO, E. C. F. C.; CARAÇA, E. B. Fonoaudiologia escolar. In: FERREIRA, L.; BARROS, M. C. P. P.; GOMES, I.; PROENÇA, M. G.; LIMONG, S. C. O.; SPINELLI, V. P.; MASSARI, I. C.; TRENCHE, M. C. B. Temas de Fonoaudiologia. São Paulo: Loyola, 1989. p. 201-209.

PEREIRA. L.; SANTOS. A. M. S.; OSBORN, E. Ação preventiva na escola: aspectos relacionados à integração professor aluno e a comunicação humana. In: CENTRO DE ESTUDOS FONOAUDIOLÓGICOS (CEFA) DA ESCOLA PAULISTA DE MEDICINA. Fonoaudiologia e Saúde Pública. São Paulo: Pró-fono, 1995. Cap. 9.

RIPLEY, S. Colaboration between general and special education teachers. USA: ERIC Digest, 1997.

SACALOSKI, M.; ALAVARSI E.; GUERRA, G. R. Fonoaudiólogo e professor: uma parceria fundamental. In.: SACALOSKI M.; ALAVARSI E.; GUERRA, G. R. Fonoaudiologia na escola. São Paulo: Lovise; 2000. p. 19-24.

SALEND, S. J.; DUHANEY, L. M. G. The impacts of inclusion on students with and without disabilities and their educators. Remedial and Special Education, v. 20 , n. 2 , p. $114-126,1999$

SILVA, M. J. P. da. A comunicação tem remédio: a comunicação nas relações interpessoais em saúde. Edições Loyola, 2006

ZORZI, J. L. Possibilidades de trabalho no âmbito escolar-educacional e nas alterações da escrita. In: GIROTO, C. R. M. Perspectivas atuais da fonoaudiologia na escola. São Paulo: Plexus, 2001. p. 43-55. 
Andréa Carla Machado - Suzelei Faria Bello Maria Amelia Almeida

\section{Correspondência}

Andréa Carla Machado - Universidade Federal de São Carlos, Rodovia Washington Luis (SP310), Km 235, Monjolinho, CEP 13565-905 - Sao Carlos, São Paulo - Brasil - Caixa-Postal: 676. E-mail: decamachado@gmail.com

Recebido em 30 de agosto de 2011

Aprovado em 02 de abril de 2012

Rev. Educ. Espec., Santa Maria, v. 25, n. 43, p. 233-248, maio/ago. 2012 Disponível em: <http://www.ufsm.br/revistaeducacaoespecial> 